\title{
Breast Cancer Selective Gene Expression and Therapy Mediated by Recombinant Adenoviruses Containing the DF3/MUC1 Promoter
}

Ling Chen, Dongshu Chen, Yoshinobu Manome, Yonghe Dong, Howard A. Fine, and Donald W. Kufe

Division of Cancer Pharmacology, Dana-Farber Cancer Institute, Harvard Medical School, Boston, Massachusetts 02115

\begin{abstract}
The high molecular weight mucin-like glycoprotein, DF3 (MUC1), is overexpressed in the majority of human breast cancers. Here we demonstrate that replication defective recombinant adenoviral vectors, containing the DF3 promoter (bp -725 to +31 ), can be used to express $\beta$-galactosidase

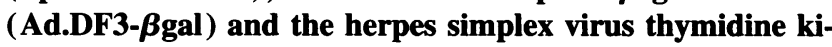
nase (HSV-tk) gene (Ad.DF3-tk) in DF3 positive breast carcinoma cell lines. In vivo experiments using breast tumor implants in nude mice injected with Ad.DF3-ßgal demonstrated that expression of the $\beta$-galactosidase gene is limited to DF3-positive breast cancer xenografts. Moreover, in an intraperitoneal breast cancer metastases model, we show that i.p. injection of Ad.DF3-tk followed by GCV treatment results in inhibition of tumor growth. These results demonstrate that utilization of the DF3 promoter in an adenoviral vector can confer selective expression of heterologous genes in breast cancer cells in vitro and in vivo. (J. Clin. Invest. 1995.96:2775-2782.) Key words: adenovirus • breast cancer - thymidine kinase $\bullet \beta$-galactosidase $\cdot$ gene therapy
\end{abstract}

\section{Introduction}

Gene therapy is a potentially novel approach to cancer treatment. In this context, transfer of suitable genetic material into a specific cell type (either tumor or host) can be used to alter the phenotype of the target cell. One such strategy is based on direct transfer of a "suicide gene" which encodes an enzyme such as herpes simplex thymidine kinase (HSV-tk) ${ }^{1}$ that can activate a prodrug within tumor cells and thereby render the tumor cells sensitive to agents which are otherwise nontoxic to the cell. For example, ganciclovir (GCV) is a nucleoside that is nontoxic to mammalian cells, but is lethal after phosphorylation in cells that express HSV-tk (1-4). While gene therapy may provide a new therapeutic approach, clinical efficacy may require gene delivery systems which possess both high gene transduction efficiency and target cell specificity.

Address correspondence to Donald W. Kufe, M.D., Division of Cancer Pharmacology, Dana-Farber Cancer Institute, 44 Binney Street, Boston, MA 02115. Phone: 617-632-3141; FAX: 617-632-2934.

Received for publication 24 July 1995 and accepted in revised form 6 September 1995.

1. Abbreviations used in this paper: Ad, adenovirus; CMV, cytomegalovirus; GCV, ganciclovir; HSV-tk, herpes simplex thymidine kinase; pfu, plaque-forming unit(s); X-gal, 5-bromo-4-chloro-3-indolyl $\beta$-Dgalactoside.

J. Clin. Invest.

(c) The American Society for Clinical Investigation, Inc.

$0021-9738 / 95 / 12 / 2775 / 08 \quad \$ 2.00$

Volume 96, December 1995, 2775-2782
Human adenoviruses are non-enveloped double-stranded DNA viruses with a genomic size of $\sim 36 \mathrm{~kb}(5,6)$. The E1 gene-deleted adenoviruses are replication defective and can be grown in a packaging cell line transformed with the E1a and E1b genes (7). Adenoviral vectors deleted at the E1 and E3 regions are capable of accommodating DNA inserts up to $8 \mathrm{~kb}$ $(8,9)$. Moreover, adenovirus-mediated gene transfer is a highly efficient means for delivery of genetic material into a wide spectrum of cells both in vitro and in animals. Although recombinant adenoviruses hold promise for in vivo gene therapy and are being tested clinically (10), one of the limitations of this vector system for cancer therapy may be the nonspecific transduction of therapeutic genes into nontarget cells. One strategy to circumvent this limitation would be to use a tumor-tissue specific/selective promoter or enhancer to direct the expression of a therapeutic gene in the desired target cells.

DF3 antigen (also designated MUC1 and episialin ) is a member of a family of high molecular weight glycoproteins which are aberrantly overexpressed in most human breast cancers. We have previously shown that monoclonal antibody mAb DF3, prepared against a membrane-enriched extract of a human breast carcinoma metastatic to liver, reacts with over $75 \%$ of primary human breast carcinomas (11). Other studies have shown that overexpression of the DF3 gene in human MCF-7 (12) and ZR75 breast cancer cells (13) is regulated at the transcriptional level. Recent cloning and characterization of the $5^{\prime}$ flanking region of DF3 gene has demonstrated that the DF3 gene expression is mainly regulated by sequences between positions -598 and $-485 \mathrm{bp}$ upstream to the transcription start site (14).

In the present work, we describe the construction of replication defective adenoviral vectors containing the $E$. coli $\beta$-galactosidase gene (Ad.DF3- $\beta$ gal) or the HSV-tk gene (Ad.DF3-tk) under control of the DF3 promoter. We have evaluated expression of the reporter gene in DF3-positive and -negative cells in vitro and in vivo. We have also assessed the ability of Ad.DF3tk to confer sensitivity to GCV in human breast cancer models in athymic nude mice. Our results suggest that an adenoviral vector system containing the DF3 promoter is capable of directing efficient and selective expression of heterologous genes in DF3-positive breast carcinomas.

\section{Methods}

Cell culture. The MCF-7, ZR-75-1, BT-20, and MDA-MB231 breast cancer cell lines were obtained from American Type Culture Collection (ATCC, Rockville, MD). The Hs578Bst myoepithelial cell line derived from normal breast tissue adjacent to a infiltrating ductal carcinoma (15) and the human T98G glioblastoma cell line were also obtained from ATCC. Cells were grown as monolayers in recommended culture medium supplemented with $10 \%$ heat-inactivated fetal bovine serum, 2 $\mathrm{mM}$ L-glutamine, $100 \mathrm{U} / \mathrm{ml}$ penicillin, and $100 \mu \mathrm{g} / \mathrm{ml}$ streptomycin. Cells were maintained in a $5 \% \mathrm{CO}_{2}$ humidified atmosphere.

Recombinant adenoviruses. Recombinant adenoviruses Ad.DF3- $\beta$ gal and Ad.CMV- $\beta$ gal derived from type 5 adenovirus (Ad 5), were produced by homologous recombination in the human embryonic kidney cell 


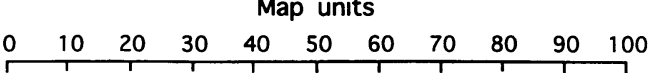

Ad 5

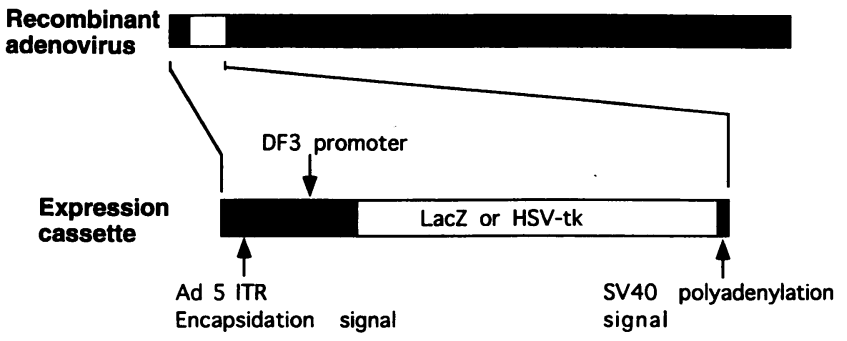

Figure 1. Schematic representation of the recombinant Ad.DF3- $\beta$ gal and Ad.DF3-tk adenoviral vectors. Ad.DF3- $\beta$ gal was constructed by insertion of a $\beta$-galactosidase (lacZ) expression cassette containing the DF3 promoter and SV40 polyadenylation signal at the deleted E1 region Ad 5 (1.3-9.2 mu). Ad.DF3-tk is a structurally similar adenovirus in which the lacZ gene is replaced by the HSV-tk gene.

line 293 (7). The DF3 5' flanking region $(-725$ to -31$)$ was inserted into XhoI and SpeI digested plasmid pCMV $\beta$ gal (provided by Dr. R. Crystal, Cornell Medical Center, NY). The resulting plasmid pDF3 $\beta$ gal contains the E. coli $\beta$-galactosidase (lacZ) gene with the SV-40 polyadenylation signal under the control of DF3 promoter and SV-40 splice donor/acceptor signal, flanked by Ad 5 map units 0.0-1.3 and 9.3-17.3 (Fig. 1). To construct Ad.DF3-tk, a 2.0-kb cDNA of HSV-tk (16) was used to replace the lacZ gene in the shuttle plasmid pDF3 $\beta$ gal (Fig. 1). The shuttle plasmids were cotransfected by calcium phosphate precipitation into 293 cells together with pJM17 plasmid containing the adenoviral genome (kindly provided by Dr. Graham, McMaster University, Ontario, Canada). Recombinant adenovirus was isolated from a single plaque and expanded in 293 cells. The viral DNA was purified and analyzed by restriction enzyme digestion and by polymerase chain reaction (PCR). A pair of primers, 5'-TCTAGACTAGTGGACCCTAGGGTTCATCGGAG-3' and 5'-AACTCGAGGATTCAGGCAGGCGCTGGCT-3' was used to amplify and verify the presence of the DF3 promoter $(-725$ to -31 ) in the viral genome. Ad.CMV- $\beta$ gal and AD.CMV-tk are structurally similar replication-deficient recombinant adenovirus in which the lacZ and HSV-tk genes, respectively, are under the control of cytomegalovirus (CMV) immediate-early promoter and enhancer. Large scale production of recombinant adenovirus was accomplished by growth in 293 cells and purification by double cesium gradient ultracentrifugation as described (17). The titers of purified adenovirus were determined by a spectrophotometer and by plaque assays.

Adenovirus infection in vitro. $24 \mathrm{~h}$ after plating, cells were infected with adenovirus at a multiplicity of infection (MOI) of 10-50. $48 \mathrm{~h}$ later or at a specified time post infection, cells were evaluated for the expression of the reporter gene or evaluated for sensitivity to GCV.

Assays for $\beta$-galactosidase. Histochemical staining with 5-bromo4-chloro-3-indolyl $\beta$-D-galactoside (X-Gal). Sections of fresh frozen tissue $(12 \mu \mathrm{m})$ or cells were fixed with $0.5 \%$ glutaraldehyde in phosphate-buffered saline (PBS) containing $1 \mathrm{mM} \mathrm{MgCl}$ for $10 \mathrm{~min}$, rinsed with $\mathrm{PBS}$, and then incubated with $\mathrm{X}-\mathrm{Gal}(1 \mathrm{mg} / \mathrm{ml}), 5 \mathrm{mM}$ $\mathrm{K}_{3} \mathrm{Fe}(\mathrm{CN})_{6}, 5 \mathrm{mM} \mathrm{K} 4 \mathrm{Fe}(\mathrm{CN})_{6}, 1 \mathrm{mM} \mathrm{MgCl}{ }_{2}$ in PBS for $4 \mathrm{~h}$.

Fluorescence-activated cell sorting (FACS) analysis. (a) Indirect immunofluorescent analysis of DF3 antigen. Cultured cells $\left(1-2 \times 10^{6}\right)$ were washed extensively with $1 \%$ bovine serum albumin (BSA) in PBS and incubated with mAb DF3 $(1 \mu \mathrm{g} / \mathrm{ml})$ or isotype identical control antibody mouse IgG (F-8765; Sigma Chemical Co., St. Louis, MO) at $4^{\circ} \mathrm{C}$ for $1 \mathrm{~h}$, and then washed with $1 \% \mathrm{BSA} / \mathrm{PBS}$. Cells were incubated with fluorescein isothiocyanate (FITC)-conjugated goat anti-mouse IgG (F2012; Sigma Chemical Co.) at $4^{\circ} \mathrm{C}$ for $1 \mathrm{~h}$, washed and analyzed on a Becton Dickinson FACScan. Intensity of fluorescence was deter- mined for 10,000 cells and compared with the fluorescence obtained using a nonreactive immunoglobulin of the same isotype. (b) FACSGAL assay (18). Briefly, $1 \times 10^{6}$ cells were suspended in $50 \mu \mathrm{l}$ of serum-free culture medium and warmed to $37^{\circ} \mathrm{C}$. An equal volume of $2 \mathrm{mM}$ fluorescein di- $\beta$-D-galactopyranoside (FDG; Molecular Probes, Eugene, OR) was added to each aliquot of cells. The cells and FDG were mixed rapidly and incubated for $1 \mathrm{~min}$ at $37^{\circ} \mathrm{C}$. Thereafter, cells were washed once with $4 \mathrm{ml}$ ice-cold PBS and maintained in ice-cold PBS until analysis on a Becton Dickinson FACScan.

Assays for GCV sensitivity in vitro. Adenovirus (Ad)-infected and noninfected cells were plated at $4 \times 10^{4}$ cells/well in six-well plates. GCV was added to the culture medium at various final concentrations (0-250 $\mu \mathrm{M})$. After 6-7 d of incubation, cells were washed with PBS and trypsinized. The number of viable cells were determined by trypan blue exclusion. Cell number was also assessed using a colorimetric cell proliferation (XTT) assay that measures the mitochondrial dehydrogenase activity of viable cells. Results are expressed as a growth ratio of the number of cells in plates containing drugs as a percentage of that in the corresponding drug-free controls.

In vivo gene transfer to human breast cancer xenografts. Female athymic nude mice (Swiss-nu/nu, Taconic, Germantown, NY), 20-25 grams, were used. For mice bearing MCF-7 or ZR-75-1 tumors, a single pellet of $17 \beta$-estradiol ( $1.7 \mathrm{mg} / 60$-d release; Innovative Research, Toledo, $\mathrm{OH}$ ) was implanted subcutaneously one day before tumor inoculation. (a) Subcutaneous tumor model. Cells (MCF-7, ZR-75-1 and MDAMB231 ) in exponential growth phase $\left(1 \times 10^{7}\right.$ in $\left.0.2 \mathrm{ml}\right)$ were injected subcutaneously in the flanks of the animals. At 4 to $6 \mathrm{wk}$ after tumor implantation, up to $5 \times 10^{8}$ plaque-forming units ( $p f u$ ) of purified recombinant adenovirus in $20 \mu \mathrm{l}$ were injected into MCF-7, ZR-75-1, and MDA-MB231 xenografts, and into limb skeletal muscle. A Hamilton syringe with a 26-gauge needle was used for injection. The needle was coated with fine charcoal particles to mark the needle tract in order to verify colocalization of the expression of the reporter gene with the viral injection. $3 \mathrm{~d}$ after adenoviral infection, the animals were killed and expression of the reporter gene in tumor xenografts and host tissues was evaluated. ( $b$ ) Intraperitoneal tumor model. MCF-7 cells $\left(5 \times 10^{6}\right)$ were injected i.p. for the development of intraperitoneal tumors (day 0 ). On days 4 and 5 after tumor cell injection, $1 \times 10^{9}$ pfu adenovirus in $0.5 \mathrm{ml}$ PBS were injected i.p. into the mice. On day 7 , the animals were treated with either saline or GCV $(125 \mathrm{mg} / \mathrm{kg}$ ) daily for $4 \mathrm{~d}$ by i.p. injection. The animals were killed at 5-6 wk after tumor inoculation. Tumors were collected and weighed for each animal.

\section{Results}

Selective expression of $\beta$-galactosidase in human cell lines in vitro. Expression of $\beta$-galactosidase was evaluated in Ad.DF3$\beta$ gal-infected MCF-7, ZR-75-1, BT-20, and MDA-MB231 breast cancer cells. In addition, Hs578Bst, a myoepithelial cell line derived from normal breast tissue and T98G, a human glioblastoma cell line were used in these studies. Each cell line was infected with either Ad.DF3- $\beta$ gal or Ad.CMV- $\beta$ gal at a MOI of 50. Expression of $\beta$-galactosidase was observed in MCF-7, ZR-75-1, and BT-20 cells infected with Ad.DF3- $\beta$ gal (Fig. $2, A-C$ ), whereas little if any $\beta$-galactosidase activity could be detected in similarly infected Hs578Bst, MDA-MB231 and T98G cells (Fig. 2, D-F). In contrast, all of these cell lines showed strong expression of $\beta$-galactosidase when infected with Ad.CMV- $\beta$ gal (Fig. $2, G-I$ ) in which the reporter gene is under control of the CMV early promoter and enhancer. MCF-7 cells infected with Ad.DF3- $\beta$ gal at an MOI of 50 exhibited highest $\beta$-galactosidase activity at day 3 to day 7 post infection. Transgene expression gradually decreased to $\sim 15 \%$ of maximum at $2 \mathrm{wk}$ after infection (data not shown).

Expression of $\beta$-galactosidase in Ad.DF3- $\beta$ gal-infected cells correlates with the expression of DF3. To assess whether 

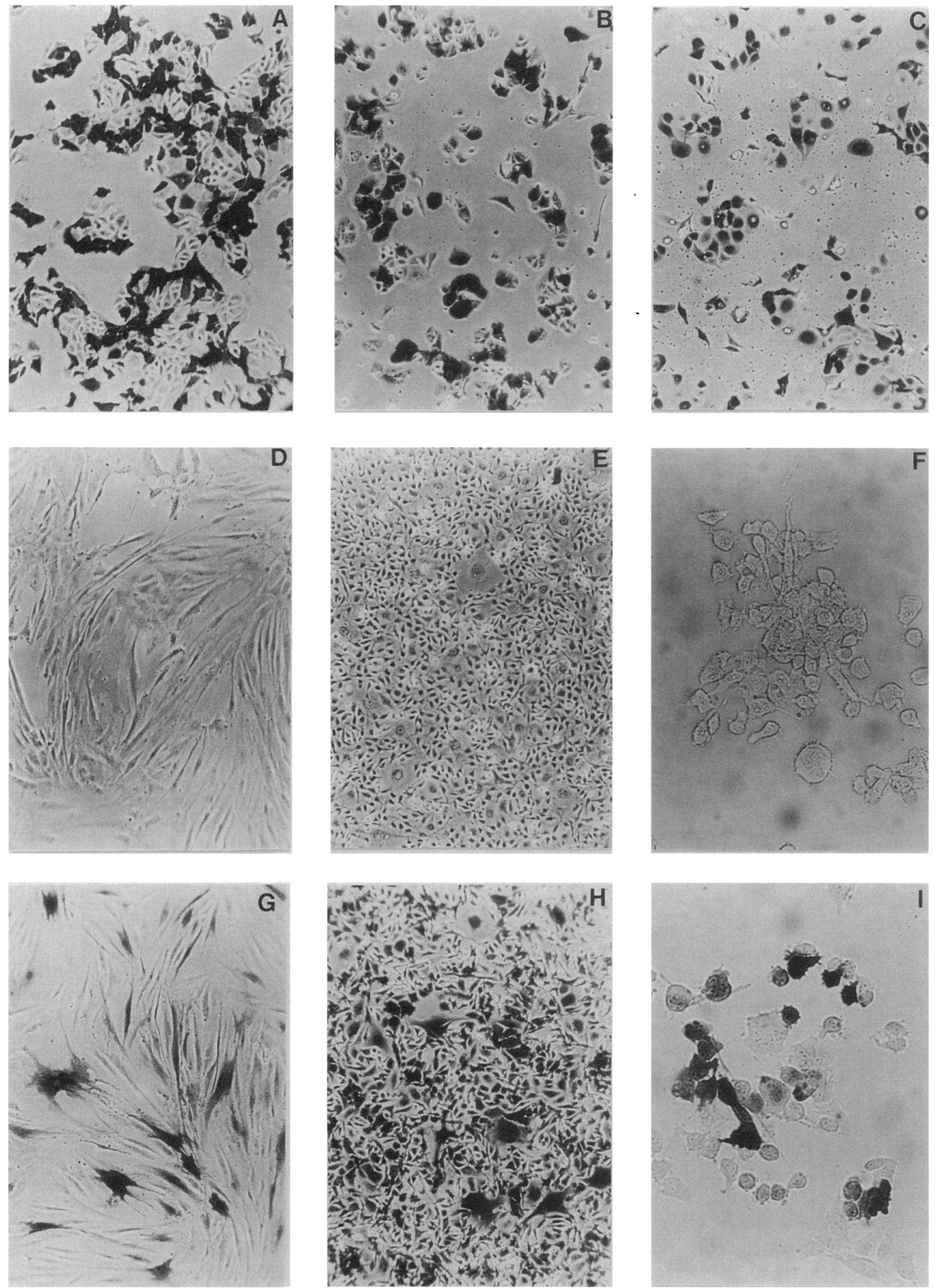

Figure 2. Expression of $\beta$-galactosidase in human cell lines infected with recombinant adenoviruses. Cells in exponential growth phase were infected with adenoviruses at an $\mathrm{MOI}=50.2 \mathrm{~d}$ after adenovirus infection, cells were fixed in $0.5 \%$ glutaraldehyde and stained with X-Gal for $4 \mathrm{~h}$. MCF7 ( $A$, DF3+), ZR-75-1 ( $B$, DF3+), BT-20 ( $C$, DF3+), Hs578Bst ( $D$, DF3-), MDA-MB231 ( $E$, DF3-), and T98G $(F$, DF3-) cells infected with Ad.DF3- $\beta$ gal. Hs578Bst $(G)$, MDA-MB231 $(H)$, and T98G $(I)$ cells infected with Ad.CMV- $\beta$ gal. All panels $100 \times$ magnification.

there is a correlation between DF3 expression and capability of these cells to express $\beta$-galactosidase after Ad.DF3- $\beta$ gal infection, we examined the presence of DF3 antigen in MCF-7, ZR75-1, and Hs578Bst cells by FACS analysis. MCF-7 and ZR-75-
1 cells exhibited strong reactivity with mAb DF3, a monoclonal antibody against DF3 antigen, while little if any mAb DF3 binding was detectable with Hs578Bst cells (Fig. $3 \mathrm{~A}$ ). Using the FACS-GAL assay, all MCF-7 and ZR-75-1 cells infected 


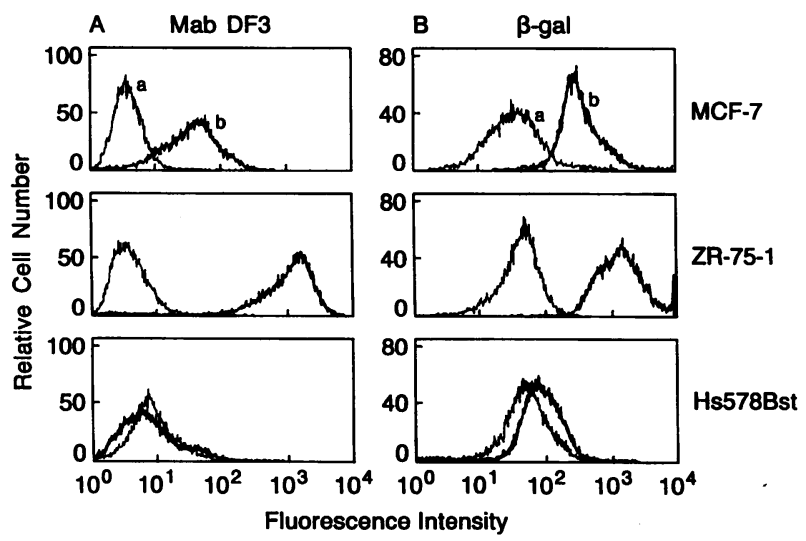

Figure 3. $\beta$-galactosidase expression in Ad.DF3- $\beta$ gal infected cells correlates with expression of DF3 antigen. ( $A$ ) FACS analysis to detect the presence of DF3 antigen in MCF-7, ZR-75-1, and Hs578Bst cell lines. Cells were incubated with mouse $\operatorname{IgG}$ as control (curve $a$ ) or MAb DF3 (curve $b$ ) and then FITC-conjugated anti-mouse IgG. (B) FACS-GAL assay to analyze $\beta$-galactosidase activity in uninfected cells (curve $a$ ) or Ad.DF3- $\beta$ gal $(\mathrm{MOI}=50)$ infected cells (curve $b$ ). $y$-axis indicates relative number of cells, $x$-axis shows fluorescence intensity.

with Ad.DF3- $\beta$ gal appear to express $\beta$-galactosidase with an increase in mean fluorescent intensity of up to 35 -fold (Fig. 3 $B)$. In contrast, there was little if any expression of $\beta$-galactosidase in Ad.DF3- $\beta$ gal-infected Hs578Bst cells (Fig. $3 B$ ). These findings support a correlation between the presence of cellular DF3 antigen and expression of $\beta$-galactosidase in Ad.DF3- $\beta$ galinfected cells.

Ad.DF3-tk sensitizes DF3-positive MCF-7 and ZR-75-1 breast cancer cells to GCV in vitro. Given the finding that the DF3 promoter can direct selective expression of a reporter gene, we replaced the $\beta$-galactosidase gene in Ad.DF3- $\beta$ gal with HSV-tk. To determine whether Ad.DF3-tk can confer sensitivity to GCV, MCF-7 and ZR-75-1 cells were transduced with Ad.DF3-tk at MOIs of 10 and 50. Ad.CMV-tk was used in order to assess HSV-tk gene expression under control of the different promoters. Infection with Ad.DF3-tk had little effect on cell viability (Fig. 4). Moreover, Ad.DF3-tk transduction conferred sensitivity of both MCF-7 and ZR-75 cells to GCV (Fig. 4, $A$ and $B$ ), while nontransduced cells or cells transduced with Ad.CMV- $\beta$ gal or Ad.DF3- $\beta$ gal (data not shown) were insensitive to GCV (Fig. 4). As previously demonstrated (19, 20 ), similar results were obtained when cells were exposed to GCV for 6-7 d or to GCV for $24 \mathrm{~h}$ followed by incubation for 5-6 d in media (data not shown). The degree of Ad.DF3-tkmediated GCV sensitivity was comparable to that obtained with Ad.DF3-tk. In contrast, when Ad.DF3-tk and Ad.CMV-tk were used to in infect DF3-negative Hs578Bst epithelial cells, only Ad.CMV-tk infected cells were sensitive to GCV (Fig. 4 C).

In vivo targeted gene expression in human breast cancer xenografts. To ascertain whether Ad.DF3- $\beta$ gal can confer selective expression of $\beta$-galactosidase in vivo, we injected up to 5 $\times 10^{8}$ pfu of Ad.DF3- $\beta$ gal into MCF-7 and ZR-75-1 cells grown as subcutaneous xenografts in athymic nude mice. $3 \mathrm{~d}$ after adenovirus infection, the tumors were excised and assayed for $\beta$-galactosidase activity. Expression of $\beta$-galactosidase was distributed extensively along the needle tract of Ad.DF3- $\beta$ gal injection (as indicated by the co-localized charcoal particles) in both MCF-7 and ZR-75-1 tumor nodules (Fig. 5, $A$ and $B$ ). Blue staining was detectable within the tumor mass, but not in

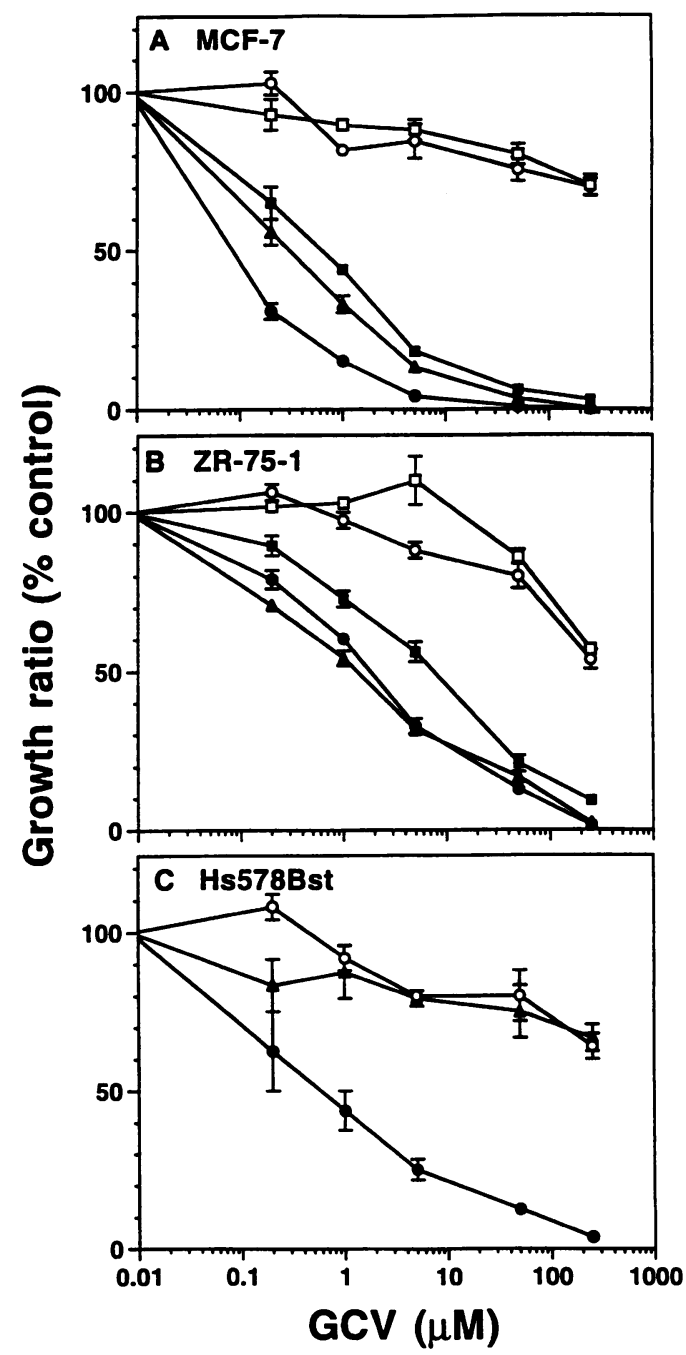

Figure 4. Ad.DF3-tk selectively sensitizes DF3-positive breast cancer cells to GCV. Cells were infected with Ad.DF3-tk or Ad.CMV-tk at MOIs of 10 to 50. Uninfected cells or cells infected with Ad.CMV$\beta$ gal were used as controls. $48 \mathrm{~h}$ later, cells were replated at $4 \times 10^{4}$ cells/well in 6-well plates. GCV was then added at concentrations ranging from 0 to $250 \mu \mathrm{M}$. After 6-7 d of incubation, viable cells were counted using trypan blue exclusion. The effect of GCV on cell survival was expressed as the growth ratio, i.e., cell number in wells containing drug as a percentage of the corresponding drug free control (mean $\pm \mathrm{SE}$ for duplicate determinations. ( $-\square-$ ) no adenovirus; ( $-\mathrm{O}-$ ) Ad.CMV- $\beta$ gal $(\mathrm{MOI}=50)$; ( - - ) Ad.DF3-tk (MOI = 10); $(-\Delta-)$ Ad.DF3-tk (MOI = 50); ( •-) Ad.CMV-tk (MOI = 50) Similar results were obtained in three separate experiments.

the surrounding normal tissue (Fig. $5 B$ ). In contrast, when Ad.DF3- $\beta$ gal was injected into DF3-negative MDA-MB231 tumors grown in nude mice, there was no detectable $\beta$-galactosidase staining along the needle tract (Fig. $5 C$ ). Intramuscular injections of Ad.DF3- $\beta$ gal also resulted in no detectable $\beta$ galactosidase activity (Fig. $5 \mathrm{D}$ ), while similar injections of Ad.CMV- $\beta$ gal into skeletal muscle was associated with strong expression of $\beta$-galactosidase (Fig. $5 E$ ).

$\beta$-galactosidase expression after systemic administration of Ad.DF3- $\beta$ gal and Ad.CMV- $\beta$ gal. To further evaluate adenovirus-mediated gene transfer to different tissues in vivo, $2 \times 10^{9}$ pfu of either Ad.CMV- $\beta$ gal or Ad.DF3- $\beta$ gal was injected via tail vein. Mice were killed $4 \mathrm{~d}$ after the injection and sections 


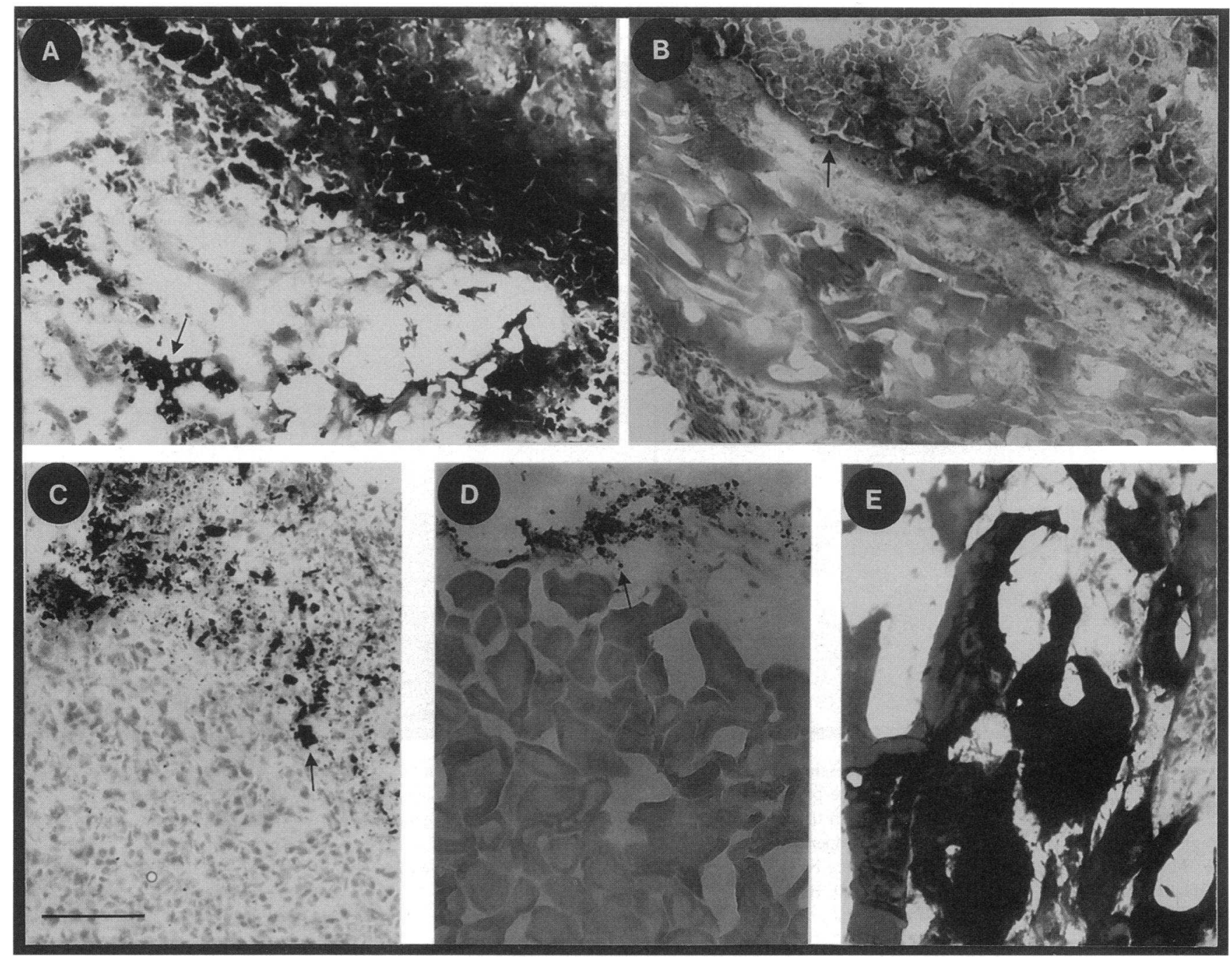

Figure 5. Ad.DF3- $\beta$ gal mediated in vivo selective expression of $\beta$-galactosidase in breast cancer cells. MCF-7, ZR-75-1, and MDA-MB231 xenografts were grown subcutaneously in athymic nude mice. Adenovirus $\left(5 \times 10^{8} \mathrm{pfu}\right)$ was injected into the tumors or mouse limb skeletal muscle using a 26-gauge needle coated with charcoal particles (indicated by the arrowhead). The tissues were harvested $3 \mathrm{~d}$ after viral injection. The frozen sections $(12 \mu \mathrm{m})$ were fixed in $0.5 \%$ glutaraldehyde and stained for $\beta$-galactosidase activity with X-Gal for $4 \mathrm{~h}$. MCF-7 (A), ZR-75$1(B)$, and MDA-MB231 $(C)$ injected with Ad.DF3- $\beta$ gal. Mouse skeletal muscle injected with Ad.DF3- $\beta$ gal $(D)$ or with Ad.CMV- $\beta$ gal $(E)$. All panels $\times 100$. Bar, $100 \mu \mathrm{m}$.

of the liver, spleen, and lung were stained for $\beta$-galactosidase activity. Systemic injection of Ad.CMV- $\beta$ gal resulted in expression of $\beta$-galactosidase in the liver parenchyma, in the splenic red pulp, and diffusely in the lung (Fig. 6 A). By contrast, there was no detectable $\beta$-galactosidase staining in these tissues in mice injected with Ad.DF3- $\beta$ gal. Several foci of $\beta$-galactosidase staining (representing $<0.1 \%$ of cells in tumor cross sections) were detected in MCF-7 tumors of animals that received systemic Ad.DF3- $\beta$ gal (Fig. $6 \mathrm{~B}$ ). However, i.p. injection of Ad.DF3- $\beta$ gal into mice bearing intraperitoneal MCF-7 tumor was associated with extensive expression of $\beta$-galactosidase in the tumor (Fig. $6 C$ ).

Treatment of intraperitoneal breast tumor. To evaluate the therapeutic efficacy of Ad.DF3-tk in human DF3-positive breast cancer cells in vivo, nude mice were inoculated i.p. with MCF7 cells. These mice developed tumor masses throughout the peritoneal cavity and $2-4 \mathrm{ml}$ of bloody ascites that contained tumor cells (Fig. 7 A ). MCF-7 tumor bearing mice were treated with Ad.DF3- $\beta$ gal + saline, Ad.DF3- $\beta$ gal + GCV, Ad.DF3-tk
+ saline and Ad.DF3-tk + GCV. Adenoviruses were injected i.p. on day 4 after tumor inoculation. GCV or saline injections were then administered on day 7 after tumor inoculation. Untreated mice and those treated with Ad.DF3- $\beta$ gal or Ad.DF3-tk + saline developed multiple intraperitoneal tumors with bloody ascites. In contrast, there was no grossly identifiable tumor mass or only a few small tumor clusters with no apparent ascites in the Ad.DF3-tk/GCV-treated mice (Fig. 7, $B$ and $C$ ). In other studies, Ad.DF3-tk $\left(2 \times 10^{9} \mathrm{pfu}\right)$ was administered intravenously by tail vein to mice with intraperitoneal tumors. The finding that treatment of these animals with GCV had no detectable therapeutic effect is in concert with the limited transduction of tumor cells after systemic administration of the vector (as shown in Fig. $6 B$ ).

\section{Discussion}

The results presented here demonstrate that the DF3 gene promoter in the context of a recombinant adenoviral vector can 


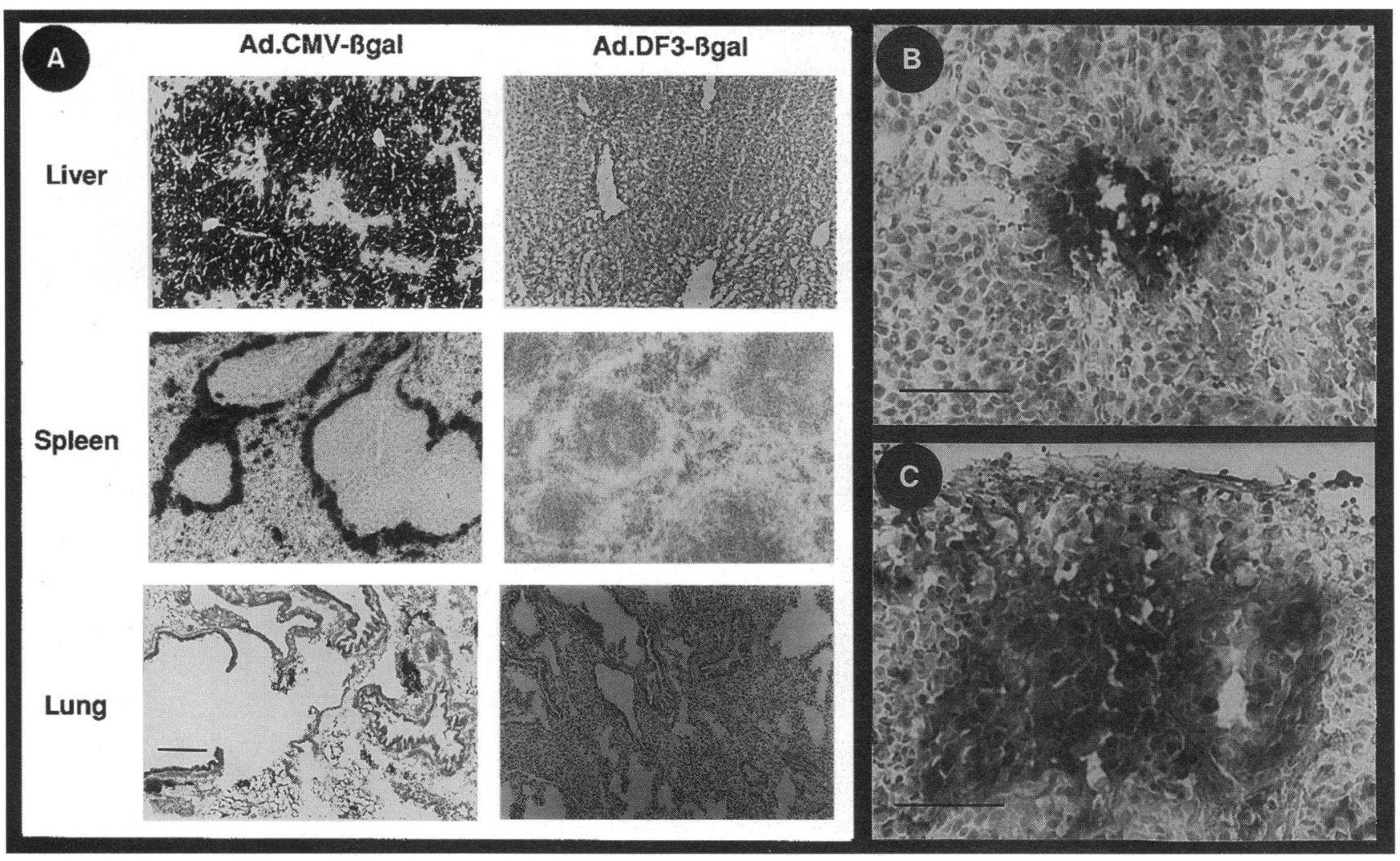

Figure 6. Distribution of $\beta$-galactosidase expression in mice injected systemically with recombinant adenoviruses. $4 \mathrm{~d}$ after adenovirus injection, sections $(12 \mu \mathrm{M})$ of the individual tissues were prepared and stained with X-Gal for $\beta$-galactosidase activity. $(A)$ Mice were injected with 2 $\times 10^{9} \mathrm{pfu}$ or Ad.DF3- $\beta$ gal or Ad.CMV- $\beta$ gal in $0.1 \mathrm{ml}$ PBS through tail vein. Expression of $\beta$-galactosidase was evaluated in liver, spleen, and lung. $\times 40$. Bar, $200 \mu \mathrm{m}$. (B) Mice bearing intraperitoneal MCF-7 tumors were given $2 \times 10^{9}$ pfu Ad.DF3- $\beta$ gal intravenously. Tumor was evaluated for $\beta$-galactosidase expression. $\times 100$. (C) Mice bearing intraperitoneal MCF-7 tumors were given $2 \times 10^{9}$ pfu Ad.DF3- $\beta$ gal i.p. Tumor was evaluated for $\beta$-galactosidase expression. $\times 100$. Bar, $100 \mu \mathrm{m}$.

confer selective expression of a reporter gene in DF3-positive human breast cancer cells in vitro and in vivo. Moreover, we demonstrate that adenovirus-mediated transduction of HSV-tk under control of the DF3 promoter can confer selective sensitivity of DF3 positive cells to GCV. These findings support the potential use of tumor-selective promoters to target expression of therapeutic genes in adenovirus-mediated gene therapy.

Currently available in vivo gene delivery systems generally lack target cell specificity. Nonviral approaches, such as ligandDNA complexes mediated gene transduction through receptor endocytosis have been reported to deliver genes through asialoglycoprotein receptors $(21,22)$. This approach, however, is largely hindered by the relatively low gene transduction efficiency due to the endosomal/lysosomal trapping of the DNA complex. Although other approaches such as the use of DNA liposome complexes $(23,24)$ and direct injection of DNA (25) have been applied for direct in vivo gene transfer, they are also limited by relative low gene transduction or restricted target tissues. Retroviral vectors have been used extensively for gene transfer, particularly for ex vivo gene therapy (26-29). However, application of retroviruses for in vivo gene therapy may be limited by low viral titers and the dependence on target cell replication. In addition, random chromosomal integration of retroviruses may raise some potential safety concerns.

Recently, recombinant adenoviruses have been employed as a highly efficient approach for in vitro and in vivo gene transfer.
Adenovirus-mediated gene transduction is independent of cell replication and the virus is capable of infecting a broad spectrum of eukaryotic cells. However, one limitation of this vector system may be nonspecific transduction of therapeutic genes into cells other than the target cells. This limitation may be critical when "suicide" genes are being delivered into tumors. Therefore, one potential strategy is to design an adenoviral vector in which a therapeutic gene can be expressed selectively in tumor cells with little or no expression in normal cells. Although adenovirus infects a wide range of cells, the present studies demonstrate that expression of a heterologous gene under the control of DF3 promoter in the context of an adenovirus vector is limited to DF3-positive breast cancer cells. Another limitation of adenoviral vectors is the induction of an immune response that precludes prolonged transgene expression and repeated administration. The development of an immune response to adenovirus, although probably limited in athymic mice (30), could also contribute to the antitumor activity associated with tk transduction and GCV therapy. Thus, studies in an animal model such as the one used in the present work may provide only certain insights into the eventual use of adenoviral vectors in humans. In addition to the E1-deleted adenoviruses, the development of new generation vectors by deleting E2a (31) or E4 (32) may further limit induction of an immune response. Finally, systemic administration of adenoviral vectors is associated with predominant transduction of hepatocytes (33-35). 


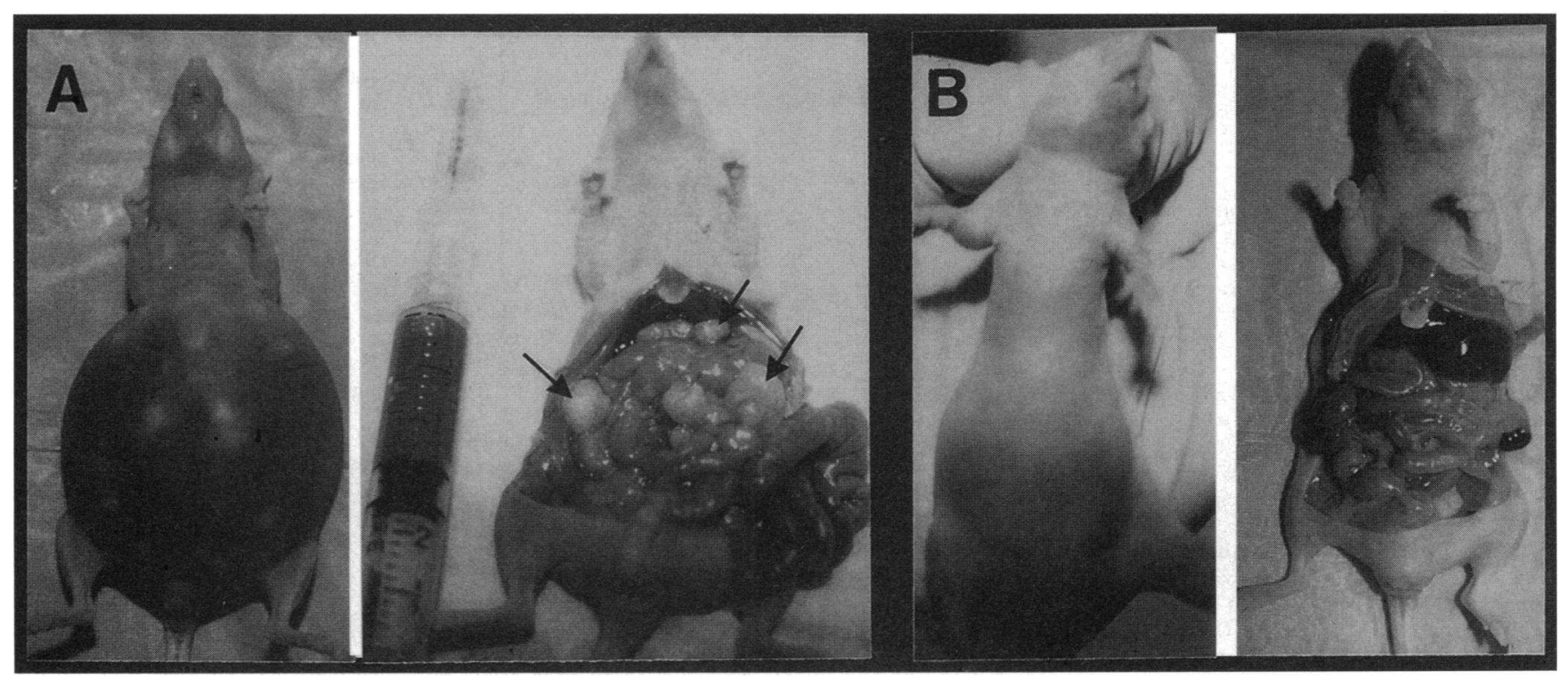

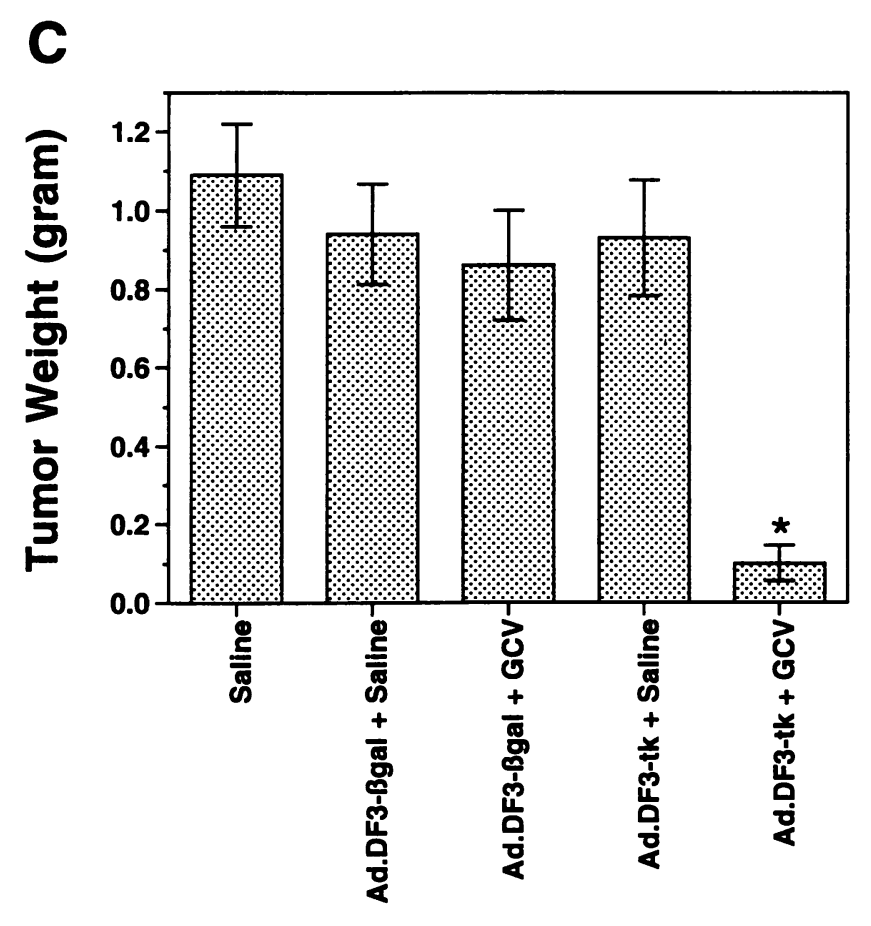

The similar findings obtained in our studies further support the present limitations in using adenoviral vectors for the treatment of a disseminated tumor. These findings also support the potential need for promoters that are not activated in hepatocytes.

To date, only a few tumor tissue-specific or -selective DNA regulatory sequences have been identified. Moreover, most studies of selective promoters to target tumor cells were performed in cell culture or ex vivo models. Selective expression in melanoma cells has been reported using plasmids containing the promoters of the genes encoding tyrosinase and tyrosinase related proteins $(36,37)$. The promoter of the $\alpha$-fetoprotein gene (38), the promoter of the oncogene ERBB2 (39), and recently the enhancer sequence $(-598$ to -485$)$ of the DF3 gene (20) have been explored in the context of retroviral vectors to direct expression of prodrug activating enzymes and to confer selective tumor killing in a number of cancer cell lines in vitro.
Figure 7. Treatment of intraperitoneal MCF-7 breast tumors. MCF-7 cells $\left(5 \times 10^{6}\right)$ were inoculated i.p. into nude mice. On days 4 and 5 , mice received i.p. injections of Ad.DF3-tk or Ad.DF3- $\beta$ gal $\left(1 \times 10^{9} \mathrm{pfu}\right)$ in $0.5 \mathrm{ml}$ PBS. GCV treatment was initiated on day 7 at a dose of $125 \mathrm{mg} /$ $\mathrm{kg}$ body weight daily via i.p. injection for $4 \mathrm{~d}$. $6 \mathrm{wk}$ after GCV treatment, animals were killed for evaluation. $(A)$ Intraperitoneal tumor in an untreated mouse, showing multiple solid tumors (arrows) and bloody ascites. ( $B$ ) Mouse treated i.p. with Ad.DF3-tk/GCV showing no evident intraperitoneal tumor. $(C)$ Tumor masses from each group were collected and weighed (mean \pm SE, $n=6$ ). In the Ad.DF3-tk + GCV treatment group, two mice had no grossly visible tumor. Similar results were obtained in three separate experiments. Asterisk, significance $(P<0.001)$ compared with other groups.

However, to our knowledge, there are no previous reports of using a tumor-selective promoter in the context of an adenovirus vector to selectively kill tumor cells in vivo. In the present studies, we have demonstrated an efficient and selective approach to target expression of heterogous genes in DF3-positive breast cancer cells. Currently, recombinant adenoviral vectors containing the DF3 promoter and other candidate therapeutic genes including cytochrome $\mathrm{P} 450(40,41)$, and cytosine deaminase $(42,43)$ are being developed.

\section{Acknowledgments}

The authors are grateful to R. Crystal and F. Graham for providing materials used for viral constructs and to $\mathrm{M}$. Abe for helpful discussions.

This investigation was supported by Department of the Army, grant DAMD 17-94-J-4394. The content of the information does not necessar- 
ily reflect the position or the policy of the government, and no official endorsement should be inferred.

\section{References}

1. Moolten, F. L., and J. M. Wells. 1990. Curability of tumors bearing herpes thymidine kinase genes transferred by retroviral vectors. J. Natl. Cancer Inst. 82:297-300.

2. Ezzeddine, Z. D., R. L. Martuza, D. Platika, M. P. Short, A. Malick, B. Choi, and X. O. Breakefield. 1991. Selective killing of glioma cells in culture and in vivo by retrovirus transfer of the herpes simplex virus thymidine kinase gene. New Biol. 3:608-614.

3. Culver, K. W., Z. Ram, S. Wallbridge, H. Ishii, E. H. Oldfield, and R. M. Blaese. 1992. In vivo gene transfer with retroviral vector-producer cells for treatment of experimental brain tumors. Science (Wash. DC). 256:1550-1552.

4. Ram, Z., K. W. Culver, S. Walbridge, R. M. Blaese, and E. H. Oldfield. 1993. In situ retroviral-mediated gene transfer for the treatment of brain tumors in rats. Cancer Res. 53:837-88.

5. Ginsberg, H. S. 1984. The Adenoviruses. Plenum Press, New York.

6. Horwitz, M. S. 1990. Adenoviridiae. In Virology. B. N. Fields and D. M. Knipe, editors. Raven Press, New York.

7. Graham, F. L., J. Smiley, W. C. Russel, and R. Nairn. 1977. Characteristics of a human cell line transformed by DNA from human adenovirus type 5. J. Gen. Virol. 36:59-72.

8. Haj-Ahmad, Y., and F. L. Graham. 1986. Characterization of an adenovirus type 5 mutant carrying embedded inverted terminal repeats. Virology. 153:2234.

9. Bett, A. J., W. Haddara, L. Prevec, and F. L. Graham. 1994. An efficient and flexible system for construction of adenovirus vector with insertions or deletions in early regions 1 and 3. Proc. Natl. Acad. Sci. USA. 91:8802-8806.

10. Crystal, R. G., N. G. McElvaney, M. A. Rosenfeld, C. Chu, A. Mastrangeli, J. G. Hay, S. T. Brody, H. A. Jaffe, N. T. Eissa, and C. Danel. 1994. Administration of an adenovirus containing the human CFTR cDNA to the respiratory tract of individuals with cystic fibrosis. Nature Genet. 8:42-50.

11. Kufe, D., G. Inghirami, M. Abe, D. Hayes, H. Justi-Wheeler, and J. Schlom. 1984. Differential reactivity of a novel monoclonal antibody (DF3) with human malignant versus benign breast tumors. Hybridoma. 3:223-232.

12. Abe, M., and D. Kufe. 1990. Transcriptional regulation of DF3 gene expression in human MCF-7 breast carcinoma cells. J. Cell. Physiol. 143:226231.

13. Kovarik, A., N. Peat, D. Wilson, S. J. Gendler, and J. Taylor-Papadimitriou. 1993. Analysis of the tissue-specific promoter of the MUCl gene. J. Biol. Chem. 268:9917-9926.

14. Abe, M., and D. Kufe. 1993. Characterization of cis-acting elements regulating transcription of the human DF3 breast carcinoma-associated antigen (MUC1) gene. Proc. Natl. Acad. Sci. USA. 90:282-286.

15. Hackett, A. J., H. S. Smith, E. L. Springer, R. B. Owens, W. A. NelsonRees, J. L. Riggs, and M. B. Gardner. 1977. Two syngeneic cell lines from human breast tissue: the aneuploid mammary epithelial (Hs578T) and the diploid myoepithelial (Hs578Bst) cell lines. J. Natl. Cancer Inst. 58:1795-1806.

16. Colbere-Garapin, F., S. Chousterman, F. Horodniceanu, P. Kourilsky, and A. C. Garapin. 1979. Cloning of the active thymidine kinase gene of herpes simplex virus type 1 in Escherichia coli K-12. Proc. Natl. Acad. Sci. USA 76:3755-3759.

17. Graham, F. L., and L. Prevec. 1991. Manipulation of adenvirus vectors. In Methods in Molecular Biology: Gene transfer and expression protocols. E. J. Murray, editor. The Humana Pres Inc., Clifton, NJ.

18. Nolan, G. P., S. Fiering, J. F. Nicolas, and L. A. Herzenberg. 1988. Fluorescence-activated cell analysis and sorting of viable mammalian cells based on beta-D-galactosidase activity after transduction of Escherichia coli lacZ. Proc. Natl. Acad. Sci. USA. 85:2603-2607.

19. Smythe, W. R., H. C. Hwang, K. M. Amin, S. L. Eck, B. L. Davidson, J. M. Wilson, L. R. Kaiser, and S. M. Albelda. 1994. Use of recombinant adenovirus to transfer the herpes simplex virus thymidine kinase (HSVtk) gene to thoracic neoplasms: an effective in vitro drug sensitization system. Cancer Res. 54:20552059.

20. Manome, Y., M. Abe, M. F. Hagen, H. A. Fine, and D. W. Kufe. 1994. Enhancer sequences of the DF3 gene regulate expression of the herpes simplex virus thymidine kinase gene and confer sensitivity of human breast cancer cells to ganciclovir. Cancer Res. 54:5408-5413.

21. Wu, G. Y., and C. H. Wu. 1988. Receptor-mediated gene delivery and expression in vivo. J. Biol. Chem. 263:14621-14624.

22. Wu, G. Y., J. M. Wilson, F. Shalaby, M. Grossman, D. A. Shafritz, and
C. H. Wu. 1991. Receptor-mediated gene delivery in vivo. Partial correction of genetic analbuminemia in Nagase rats. J. Biol. Chem. 266:14338-14342.

23. Nabel, E. G., G. Plautz, and G. J. Nabel. 1990. Site-specific gene expression in vivo by direct gene transfer into the arterial wall. Science (Lond.). 249:1285-1288

24. Nabel, E. G., D. Gordon, Z. Y. Yang, L. Xu, H. San, G. E. Plautz, B. Y. Wu, X. Gao, L. Huang, and G. J. Nabel. 1992. Gene transfer in vivo with DNAliposome complexes: lack of autoimmunity and gonadal localization. Hum. Gene Ther. 3:649-656.

25. Wolff, J. A., R. W. Malone, P. Williams, W. Chong, G. Acsadi, A. Jani, and P. L. Felgner. 1990. Direct gene transfer into mouse muscle in vivo. Science (Wash. DC). 247:1465-1468

26. Culver, K., K. Cornetta, R. Morgan, S. Morecki, P. Aebersold, A. Kasid, M. Lotze, S. A. Rosenberg, W. F. Anderson, and R. M. Blaese. 1991. Lymphocytes as cellular vehicles for gene therapy in mouse and man. Proc. Natl. Acad. Sci. USA. 88:3155-3159.

27. Wilson, J. M., M. Grossman, S. E. Raper, J. Baker, Jr., R. S. Newton, and J. G. Thoene. 1992. Ex vivo gene therapy of familial hypercholesterolemia. Hum. Gene Ther. 3:179-222.

28. Dranoff, G., E. Jaffee, A. Lazenby, P. Golumbek, H. Levitsky, K. Brose, V. Jackson, H. Hamada, D. Pardoll, and R. C. Mulligan. 1993. Vaccination with irradiated tumor cells engineered to secrete murine granulocyte-macrophage colony-stimulating factor stimulates potent, specific, and long-lasting anti-tumor immunity. Proc. Natl. Acad. Sci. USA. 90:3539-3543.

29. Jaffee, E. M., G. Dranoff, L. K. Cohen, K. M. Hauda, S. Clift, F. F. Marshall, R. C. Mulligan, and D. M. Pardoll. 1993. High efficiency gene transfer into primary human tumor explants without cell selection. Cancer Res. 53:2221 2226.

30. O'Malley Jr., B. W., S.-H. Chen, M. R. Schwartz, and S. L. C. Woo 1995. Adenovirus-mediated gene therapy for human head and neck squamous cell cancer in a nude mouse model. Cancer Res. 55:1080-1085.

31. Engelhardt, J. F., X. Ye, B. Doranz, and J. M. Wilson. 1994. Ablation of E2A in recombinant adenoviruses improves transgene persistence and decreases inflammatory response in mouse liver. Proc. Natl. Acad. Sci. USA. 91:61966200

32. Wadsworth, S. C., D. Armentano, C. Sookdeo, L. Cardoza, P. Berthelette, and A. E. Smith. 1995. Regulation of viral and therapeutic gene expression in adenovirus vectors. J. Cell. Biochem. 21 a:C6-450 (Abstr).

33. Herz, J., and R. D. Gerard. 1993. Adenovirus-mediated transfer of low density lipoprotein receptor gene acutely accelerates cholesterol clearance in normal mice. Proc. Natl. Acad. Sci. USA. 90:2812-2816.

34. Kass-Eisler, A., E. Falck-Pederson, D. H. Elfenbein, M. Alvira, P. M Buttrick, and L. A. Leinwand. 1994. The impact of developmental stage, route of administration and the immune system on adenovirus-mediated gene transfer. Gene Therapy. 1:395-402

35. Huard, J., H. Lochmüller, G. Acsadi, A. Jani, B. Massie, and G. Karpati 1995. The route of administration is a major determinant of the transduction efficiency of rat tissues by adenoviral recombinants. Gene Therapy. 2:107-115.

36. Vile, R. G., and I. R. Hart. 1993. In vitro and in vivo targeting of gene expression to melanoma cells. Cancer Res. 53:962-967.

37. Vile, R. G., and I. R. Hart. 1993. Use of tissue-specific expression of the herpes simplex virus thymidine kinase gene to inhibit growth of established murine melanomas following direct intratumoral injection of DNA. Cancer Res. 53:38603864

38. Huber, B. E., C. A. Richards, and T. A. Krenitsky. 1991. Retroviralmediated gene therapy for the treatment of hepatocellular carcinoma: an innovative approach for cancer therapy. Proc. Natl. Acad. Sci. USA. 88:8039-8043.

39. Harris, J. D., A. A. Gutierrez, H. C. Hurst, K. Sikora, and N. R. Lemoine. 1994. Gene therapy for cancer using tumor-specific prodrug activation. Gene Therapy. 1:170-175.

40. Wei, M. X., T. Tamiya, M. Chase, E. J. Boviatsis, T. K. H. Chang, N. W. Kowall, F. H. Hochberg, D. J. Waxman, X. O. Breakefield, and E. A. Chiocca. 1994. Experimental tumor therapy in mice using the cyclophosphamideactivating cytochrome $\mathrm{P} 45 \mathrm{O} 2 \mathrm{~B} 1$ gene. Hum. Gene Ther. 5:969-978.

41. Chen, L., and D. J. Waxman. 1995. Intratumoral activation and enhanced chemotherapeutic effect of oxazaphosphorines following cytochrome P450 gene transfer: development of a combined chemotherapy/cancer gene therapy strategy. Cancer Res. 55:581-589.

42. Mullen, C. A., M. Kilstrup, and R. M. Blaese. 1992. Transfer of the bacterial gene for cytosine deaminase to mammalian cells confers lethal sensitivity to 5-fluorocytosine: a negative selection system. Proc. Natl. Acad. Sci. USA. 89:33-37.

43. Huber, B. E., E. A. Austin, S. S. Good, V. C. Knick, S. Tibbels, and C. A. Richards. 1993. In vivo antitumor activity of 5-fluorocytosine on human colorectal carcinoma cells genetically modified to express cytosine deaminase. Cancer Res. 53:4619-4626. 